\title{
Efficient photocatalytic degradation of aniline blue under solar irradiation by ternary cobalt ferrite / graphitic carbon nitride / bentonite nanocomposite.
}

Debasish Guha Thakurata ( $\sim$ guhathakuratadebasish@gmail.com )

National Institute of Technology Silchar

Krishna Chandra Das

GC College: Gurucharan College

Siddhartha Sankar Dhar

National Institute of Technology Silchar

\section{Research Article}

Keywords: Nanocomposite, Aniline blue, Advanced Oxidation Process (AOP), Photo-Fenton

Posted Date: April 19th, 2021

DOl: https://doi.org/10.21203/rs.3.rs-302118/v1

License: (c) (1) This work is licensed under a Creative Commons Attribution 4.0 International License.

Read Full License

Version of Record: A version of this preprint was published at Environmental Science and Pollution Research on January 17th, 2022. See the published version at https://doi.org/10.1007/s11356-02118242-3. 


\section{Abstract}

The current research describes the synthesis, characterization, and application of $\mathrm{CoFe}_{2} \mathrm{O}_{4} / \mathrm{g}$ $\mathrm{C}_{3} \mathrm{~N}_{4}$ /Bentonite as a novel nanocomposite for the efficient degradation of aniline blue under solar irradiation. Powder XRD, TIR, SEM, TEM, VSM, and UV-DRS were used to describe the formation and morphology of the composite. The composite has been used as a heterogeneous photo catalyst to degrade aniline blue in the presence of $\mathrm{H}_{2} \mathrm{O}_{2}$. In the presence of $\mathrm{H}_{2} \mathrm{O}_{2}$ in solar radiation, it was possible to degrade $88.5 \%$ of $10 \mathrm{ppm}$ aniline blue solution just in 50 minutes using $50 \mathrm{mg}$ of the composite. The improvement in photodegradation rate in the existence of $\mathrm{H}_{2} \mathrm{O}_{2}$ was attributed to the advanced oxidation process (AOP) mechanism of Photo Fenton involving the production of reactive hydroxyl and perhydroxyl radicals. The degradation was found to follow 1 st order kinetics with high regression coefficient with elevated rate constant.

\section{Introduction}

Aniline Blue (AB) is an acidic dye that belongs to the triphenylmethane class of dye [Egzar et al. 2013]. This dye is readily soluble [Lorenc-Grabowska and Gryglewicz 2007.] in water and is extensively used in different textile industries for dying of nylon, wool, silk, and cotton for which its presence in the industrial effluents may contribute aquatic environmental contamination [Eykholt and Davenport 1998]. Besides aniline blue is exceptionally steady for which its occupancy time in the aquatic environment is extremely high [Pare et al. 2008.]. This dye is also identified as china blue, Marine blue and soluble blue 3M. Aniline Blue has a characteristic of two benzene rings attached to the central carbon atom in addition to a $p$ quinoid group which acts as the chromophore along with $-\mathrm{NH}_{2}$ and $-\mathrm{NR}_{2}$ groups as auxochromes [Sirés et al. 2008]. Usually, aniline blue is considered as the xenobiotic compounds, recalcitrant molecules, and noxious substances to microorganisms, animals, and plants. Due to the poor competence of conventional supervision, this dye sustains more in industrial wastewaters and dirt [Azmi et al.1998, Culp and Beland1996].

Effluents from the textile industry containing different toxic organic dyes pose a serious threat to our aquatic environments [Daneshvar et al. 2003, Ledakowicz and Gonera1999]. These dyes have a very complex structure and generate carcinogenicity in the course of hydrolysis, oxidation, and other chemical reactions [Ooi et al. 2012, Hayati and Mahmoodi2012, Man et al. 2012]. Different conventional techniques such as biological treatment, reverse osmosis, and activated carbon adsorption are in force to eliminate such toxicity from the aquatic environment. However in modern research advanced oxidation process (AOPs) which account for photocatalysis [Rauf and Ashraf 2009, Liu et al. 2011] and Fenton's processes [Alnuaimi et al. 2007, Bouasla et al. 2010] are considered as the most encouraging method for organic dye degradation from the aquatic environment. The advanced oxidation process utilizes the in situ generations of hydroxyl and superoxide radicals as an oxidizing agent which initiate the sequence of a chemical reaction and smash down the complex molecules in less toxic components [Rauf and Ashraf 2012]. Photocatalyst having band gap in the range of 1.1-3.0 eV makes use of visible light to degrade 
organic dyes competently [Vijayaraghavan et al. 2016]. Spinel metal ferrites with distinctive structural features and two or more cations along with imperfect oxygen sub lattice along with a narrow band gap play a significant role in the photodegradation [Dom et al. 2011]. Metal ferrites have recently received a lot of attention for their use as visible light photocatalysts for the degradation of organic dyes in water. One more benefit of using ferrites is their magnetic nature. Since iron (III) oxides are especially much magnetic materials [Machala et al. 2011], and hence ferrites are used alone as photocatalysts in the motive that they can be easily detached from the reaction medium easily [Ao et al. 2008]. The Pbs quantum dots decorated $\mathrm{ZnO} / \mathrm{TiO}_{2}$ photocalyst exhibit a superior aniline blue degradation efficiency and photocatylytic activity[Lee et al. 2018]. In UV/solar radiation, 3d series transition metal ions doped in $\mathrm{TiO}_{2}$ show enhanced photodegradation potential of aniline blue. [Devi et al. 2010]. Different semiconducting nanomaterials like $\mathrm{ZnO}, \mathrm{ZnS}$ and $\mathrm{SnO}_{2}$ has been investigated for efficient degradation of aniline blue in visible light [Egzar et al. 2013]. Even though literature assessment supports some efficient mode of degradation of aniline blue by different nano materials but the application of metal ferrite based ternary composite is still unexplored in this category of effort. Considering this aspect, the present paper discusses the novel ternary cobalt ferrite-based nanocomposite with narrow band gap of $1.59 \mathrm{eV}$ for efficient degradation of aniline blue in visible light radiation. The physical and optical properties were documented by FTIR, powdered XRD, VSM, SEM, TEM and UV-vis-DRS techniques.

\section{Experimental}

\subsection{Materials}

Merck supplies iron (III) nitrate nanohydrate $\left[\mathrm{Fe}\left(\mathrm{NO}_{3}\right)_{3} \cdot 9 \mathrm{H}_{2} \mathrm{O}\right]$, cobalt nitrate hexahydrate $\left[\mathrm{Co}\left(\mathrm{NO}_{3}\right)_{3} \cdot 6 \mathrm{H}_{2} \mathrm{O}\right]$, urea, including sodium hydroxide $(\mathrm{NaOH})$. Sigma-Aldrich provides hydrogen peroxide $(6 \%)$, bentonite, and aniline blue. Without any further purification, all chemicals were utilised for synthesis. Cinnamon is collected from local market.

\subsection{Preparation of CinnamonExtract Assisted Cobalt Ferrite.}

Cobalt ferrite $\left(\mathrm{CoFe}_{2} \mathrm{O}_{4}\right)$ nanoparticles were synthesized via self combustion using aqueous extract of cinnamon followed by calcinations in muffle furnace [Deraz2010, Kooti et al. 2013]. 5mM ferric nitrate [Fe $\left(\mathrm{NO}_{3}\right)_{3} \cdot 9 \mathrm{H}_{2} \mathrm{O}$ ] and $2.5 \mathrm{mM}$ cobalt nitrate [ $\mathrm{Co}\left(\mathrm{NO}_{3}\right)_{2} \cdot 6 \mathrm{H}_{2} \mathrm{O}$ ] were added slowly in the aqueous cinnamon extract. This mixture $(\mathrm{pH}=2)$ is heated at $80^{\circ} \mathrm{C}$ to get a gel like substance. The reddish-brown gel like substance was again heated on a heater at $250^{\circ} \mathrm{C}$ to decompose completely by self combustion. The ample powder so obtained is finally calcined at $600^{\circ} \mathrm{C}$ for 3 hours to get fine crystals of Cobalt ferrites.

\subsection{Preparation of Graphitic Carbon Nitride.}

Graphitic carbon nitride $\left(\mathrm{g}-\mathrm{C}_{3} \mathrm{~N}_{4}\right)$ was prepared by heat treatment of urea under ambient pressure in a Muffle Furnace (Isotemp Programmable Muffle Furnace 650-750 Series, Fisher Scientific) for 3 hours at 
$600^{\circ} \mathrm{C}$ to conclude the reaction. The resulting yellowish powder was washed with distilled water to eliminate any remaining matter adsorbed on it and lastly dried up at $80^{\circ} \mathrm{C}$.

\subsection{Fabrication of Ternary Composite.}

Two stages have been used to develop the ternary nanocomposite. First, a binary composite of nickel ferrite and graphitic nitride was developed, and this binary composite was then converted into a ternary composite by introducing bentonite. In a distinctive procedure $100 \mathrm{mg}$ of cobalt ferrite and $80 \mathrm{mg}$ of graphitic carbon nitride mixed homogeneously by using mortar- pestle for 30 minutes. The solid mixture is calcined at $400^{\circ} \mathrm{C}$ for 2 hours. To achieve uniform dispersion, the binary mixture was dissolved in distilled water and sonicated for 30 minutes. Centrifugation was used to separate the solid binary mixture. In another experiment, $50 \mathrm{mg}$ of bentonite was dissolved in $50 \mathrm{~mL}$ deionized water and magnetically stirred. The solid binary composite was introduced to this solution and stirred for 12 hours. After that, centrifugation has been used to extract the ternary composite.

\subsection{Study of Photocatalytic Degradation of Aniline Blue (AB)}

Photocatalytic activity of the as synthesized $\mathrm{CoFe}_{2} \mathrm{O}_{4} / \mathrm{g}-\mathrm{C}_{3} \mathrm{~N}_{4}$ /bentonite ternary composite was assessed by degrading aniline blue $(A B)$ under solar irradiation. In a typical experiment, 10mg, $30 \mathrm{mg}$ and $50 \mathrm{mg}$ of composite was introduced into $60 \mathrm{~mL}$ of $10 \mathrm{ppm}$ aniline blue solution with $1 \mathrm{~mL}$ of $10 \%$ hydrogen peroxide $\left(\mathrm{H}_{2} \mathrm{O}_{2}\right)$ and stirred in absence of light for 30 min to reach adsorption-desorption equilibrium. Under constant stirring, the mixture was exposed to solar radiation. The degradation of the dye was monitored periodically with the help of spectrophotometer (Shimazu UV-1900i) by withdrawing $4 \mathrm{~mL}$ of the mixture and centrifuging immediately $(5 \mathrm{~min}, 3000 \mathrm{rmp})$. The absorbance was recorded over a wavelength range of 200 to $800 \mathrm{~nm}$. The eq. (1) has been used to evaluate the catalytic degradation efficiency.

\section{See formula 1 in the supplementary files.}

Where, $A_{0}$ is the absorbance of $A B$ before degradation and $A$ is the absorbance of $A B$ after degradation.

\section{Results And Discussion}

\subsection{FTIR Analysis}

Careful observation on the FTIR spectra of cobalt ferrite fig. 1(a) shows intense peaks at $459 \mathrm{~cm}$ ${ }^{-1}$ and $615 \mathrm{~cm}^{-1}$ corresponding to intrinsic stretching vibrations of $\mathrm{Fe}-\mathrm{O}$ at the tetrahedral site and $\mathrm{Co}-\mathrm{O}$ at the octahedral site. $\mathrm{Co}^{2+}$ ions prefer to be in the octahedral region, whereas $\mathrm{Fe}^{3+}$ ions prefer to be in both the octahedral and tetrahedral sites. Further observations show strong absorptions at $1104 \mathrm{~cm}^{-1}$ is the same as phenolic hydroxyl group of flavonoides type of compound in the cinnamon extract [De et al. 2018]. The standard stretching modes of $\mathrm{CN}$ heterocycles were assigned to the different characteristic bands in the FTIR spectra of $\mathrm{g}-\mathrm{C}_{3} \mathrm{~N}_{4}$ in the range 1200 to $1700 \mathrm{~cm}-1$. [fig. 1(b)] is in good agreement with 
the literature [Shi et al. 2015]. The FTIR spectra of the ternary composite fig. 1(c) assign all the characteristic band of individual components present in it. The sharp peaks in the range 460- $532 \mathrm{~cm}^{-1}$ are due to $\mathrm{M}-\mathrm{O}$ bond in the tetrahedral and octahedral sites. Distinct peak on $811 \mathrm{~cm}^{-1}$ signifies bending vibration of heptazine of $\mathrm{g}-\mathrm{C}_{3} \mathrm{~N}_{4}$. Separate peak at $1030 \mathrm{~cm}^{-1}$ same as to the presence of bentonite in the composite. Three peaks in the range 1430-1620 correspond to heptazine derived repeating unit of g$\mathrm{C}_{3} \mathrm{~N}_{4}$. The broad band in the range $3188-3370 \mathrm{~cm}^{-1}$ is due to partial condensation and absorption of water molecule.

\subsection{XRD Analysis}

The XRD blueprint of $\mathrm{CoFe}_{2} \mathrm{O}_{4}, \mathrm{~g}-\mathrm{C}_{3} \mathrm{~N}_{4}$ and $\mathrm{CoFe}{ }_{2} \mathrm{O}_{4} / \mathrm{g}-\mathrm{C}_{3} \mathrm{~N}_{4} /$ Bentonite are presented in the figure $2 \mathrm{a}, \mathrm{b}$ and c). In fig. 2(a) the characteristic peaks at an angle $2 \theta=18.99,32.13$ and 35.58 corresponds to the plane (111), (220) and (311) for the $\mathrm{CoFe}_{2} \mathrm{O}_{4}$ sample precisely corresponding with the JCPDS card No. 770426. Further the creation of the $\mathrm{g}-\mathrm{C}_{3} \mathrm{~N}_{4}$ was justified by the presence of the peaks at $2 \theta$ angles 12.99 and 27.54 corresponding to (100) and (002) planes (fig. 2 b). Intense peaks of the XDR pattern of the composite fig. 2(c) indicate high crystalline nature of the substance. The position of the peaks of the components including bentonite at an angle $2 \theta=20.64,26.52$, and 54.00 corresponds to (110), (210) and (144) planes as reported in literature [Hebbar et al. 2018] is well matched, which confirms the composite formation. The average crystallite diameter (Dc) of $\mathrm{CoFe}_{2} \mathrm{O}_{4}$ particles and $\mathrm{CoFe}_{2} \mathrm{O}_{4} / \mathrm{g}-\mathrm{C}_{3} \mathrm{~N}_{4} /$ bentonite nanocomposite was deliberate to be $26.62 \mathrm{~nm}$ and $30.92 \mathrm{~nm}$ respectively by the Debye-Scherrer formula [Bunaciu et al. 2015]. The increase in the value of crystallite size of the composite compare to cobalt ferrite confirms the encapsulation of the ferrite core by graphitic carbon nitride and bentonite.

\subsection{VSM Analysis}

Vibrating sample magnetometers were used to implement magnetic studies upon this synthesized cobalt ferrite nanoparticles and ternary composites. Magnetic parameters such as remanent magnetization (Mr), saturation magnetization (Ms) and coercivity $(\mathrm{Hc})$ are shown in table.1.

\section{Table.1: VSM parameters of Cobalt ferrite and the ternary composite.}

\begin{tabular}{|c|c|c|c|}
\hline Sample & Magnetic Parameters & & \\
\hline Ms (emu/g) & $\mathrm{Hc}(\mathrm{Oe})$ & $\operatorname{Mr}(\mathrm{emu} / \mathrm{g})$ & \\
\hline $\mathrm{CoFe}_{2} \mathrm{O}_{4}$ & 4.9348 & 1048.3 & 1.1576 \\
\hline $\mathrm{CoFe}_{2} \mathrm{O}_{4} / \mathrm{g}-\mathrm{C}_{3} \mathrm{~N}_{4} /$ Bentonite & 0.8618 & 126.05 & 58.12 \\
\hline
\end{tabular}

The hysteresis loop (Fig. 3) obtained indicates the ferromagnetic behaviors of the cobalt ferrite nanoparticles with saturation magnetization value $4.9348 \mathrm{emu} / \mathrm{g}$. The abrupt drop in the saturation 
magnetization value of the ternary composite is due to incorporation of nonmagnetic graphitic carbon nitride and bentonite in the composite.

\subsection{SEM Analysis}

SEM micrographs of cobalt ferrite, graphitic carbon nitride, bentonite and the ternary nanocomposite are shown in the fig.4.The micrograph of the composite (F) shows that the semiconducting graphitic carbon nitride and bentonite segments are covered over cobalt ferrite consistently. The spherical encapsulated shape of the particle confirms the composite formation within the size range of 50 micro meters.

\subsection{TEM Analysis}

The phase compositions of the ternary composite were studied using transmission electron microscopy. Fig. 5 depicts a TEM representation of the composite. TEM picture of ternary composite fig.5 (A, B, C, D) indicates that the bentonite and graphitic carbon nitride encapsulated composite particles are almost nearly spherical and the average sizes of particles were found to be $49.29 \mathrm{~nm}$. The crystalline nature of the nanocomposite was confirmed SAED analysis fig.5 (F). Leading edge of lattice $0.410 \mathrm{~nm}$ relates to the [211] plane of bentonite, $0.272 \mathrm{~nm}$ is equivalent to [100] plane of $\mathrm{g}-\mathrm{C}_{3} \mathrm{~N}_{4}$ and $0.411 \mathrm{~nm}$ to the [111] plane of cobalt ferrite. The ternary nature of the composite is verified by the three important planes in this composite obtained from HR-TEM (fig.5 E).

\subsection{UV-DRS Analysis.}

The plot of reflectance versus wavelength of the component material and composite confirms that the absorption of light will takes place in the solar radiation's visible spectrum. In addition, the measured band gap in the material and in the composite as obtained from the Tauc's plot reveals that the composite can efficiently degrade the dye in the solar radiation.

\subsection{Investigation of aniline blue (AB) degradation by nanocomposite}

The photocatylytic performance of the ternary composite was assessed by degrading aniline blue (AB) in presence of $10 \% \mathrm{H}_{2} \mathrm{O}_{2}$ in the acidic medium under solar irradiation. The time-dependent aniline blue degradation with different composite amounts is shown in the figs.7a, 7b and7c.

When $10 \mathrm{mg}$ of composite is used along with $1 \mathrm{ml}$ of 10 percent $\mathrm{H}_{2} \mathrm{O}_{2} 50 \%$ degradation of $A B$ is achieved in $50 \mathrm{~min}$. As soon as $30 \mathrm{mg}$ and $50 \mathrm{mg}$ composites are used concurrently in the same condition, the degradation percentage rises to $77.5 \%$ and $88.5 \%$.

The kinetics of $A B$ degradation can be formulated as;

$\ln \left(\mathrm{C}_{0} / \mathrm{C}\right)=\mathrm{kt}$ 
where ' $\mathrm{C}_{0}$ ' is the initial concentration of $A B$ and ' $C$ ' is the concentration of $A B$ after certain time ' $t$ ' with rate constant ' $\mathrm{k}$ ' of the reaction. Since Beer-Lambert's law states that both absorbance and concentration are directly proportional, the concentration should be used to replace the absorbance. Plots of In $\mathrm{CO} / \mathrm{C}$ versus time (t) at $600 \mathrm{~nm}$ for three different composite quantities revealed that they were all linear as shown in the figures $8(a, b$ and $c)$.

From this linear plot the calculated rate constants are found to be $0.0132,0.0323$ and 0.0443 respectively. In the kinetics plots, the regression correlation coefficient $\left(R^{2}\right)$ variables are found to be $0.9198,0.9840$ and 0.9849 respectively. These values suggest that the reaction rate seems to be very moderate in the presence of $\mathrm{H}_{2} \mathrm{O}_{2}$. Figure $9(\mathrm{a}, \mathrm{b}$, and $\mathrm{c})$ demonstrates that $\mathrm{C} / \mathrm{C}_{0}$ decreases exponentially with time, suggesting that the degradation follows 1 st order kinetics.

\subsection{A plausible mechanistic approach to the degradation of Aniline Blue (AB) under solar irradiation in presence of $\mathrm{H}_{2} \mathrm{O}_{2}$.}

Hydrogen peroxide assisted photodegradation of $A B$ in solar radiation by Cobalt ferrite composite having $\mathrm{g}-\mathrm{C}_{3} \mathrm{~N}_{4}$ as one of the components may takes place through Photo Fenton mechanism of advanced oxidation process (AOP). Here $\mathrm{Fe}(\mathrm{II})$ of cobalt ferrite and $\mathrm{H}_{2} \mathrm{O}_{2}$ efficiently generate hydroxyl radical which degrade the dye successfully. Moreover, the inclusion of $\mathrm{g}-\mathrm{C}_{3} \mathrm{~N}_{4}$ in the composite significantly reduces the composite's band gap and increases the composite's potential for charge transfer and also facilitates the generation of electron-hole pairs, resulting in hydroxyl radical generation [Mushtaqet al. 2020, Zhanget al. 2017, Rubioet al. 2015 and Sun et al. 2015]. The reactions behind the degradation of aniline blue by Photo Fenton process can be depicted as follows[Das and Dhar 2020]and is shown in the figure10. Please see reactions in the supplementary files.

\subsection{Comparison with other Composite/ Materials for aniline blue degradation.}

Heterojunction nanocomposite dependent on cobalt ferrite has still not been thoroughly investigated, particularly in the area of toxic aniline blue degradation in aqueous solution. Some reported works are tabulated as under.

Table. 2 Correlation of efficiency of synthesized composite with some previously documented materials designed for photocatalytic degradation of aniline blue. 


\begin{tabular}{|llllll|}
\hline $\begin{array}{l}\text { Sl. } \\
\text { No }\end{array}$ & Composite $/$ Material & Dose & Time & Efficiency & Reference \\
\hline 1. & $\mathrm{PbS} / \mathrm{ZnO} / \mathrm{TiO}_{2}$ & - & $300 \mathrm{~min}$ & $82 \%$ & [Lee et al.2018] \\
\hline 2. & $\mathrm{Mn}^{2+}$ dopped polycrystalline titania & $150 \mathrm{mg}$ & $140 \mathrm{~min}$ & $100 \%$ & [Devi et al. 2010] \\
\hline 3. & $\mathrm{ZnO}$ & $10 \mathrm{mg}$ & $30 \mathrm{~min}$ & $75 \%$ & [Egzar et al. 2013] \\
\hline $\mathbf{4}$ & Cobaltl Ferrite/ $\mathrm{g}-\mathrm{C}_{3} \mathrm{~N}_{4} /$ Bentonite & $50 \mathrm{mg}$ & $50 \mathrm{~min}$ & $88.5 \%$ & This Work \\
\hline
\end{tabular}

\section{Conclusion}

In a stepwise protocol, a novel type of ternary nanocomposite $\mathrm{CoFe} \mathrm{O}_{4} / \mathrm{g}-\mathrm{C}_{3} \mathrm{~N}_{4}$ /Bentonite was productively fabricated. The composite was thoroughly examined by powder FTIR, XRD, VSM, SEM, TEM and UV-DRS studies. The composite's photo degradation ability to degrade aniline blue in the existence of $\mathrm{H}_{2} \mathrm{O}_{2}$ in solar radiation is well documented through spectrochemical observations. The composite can degrade aniline blue up to the extent of $88.5 \%$ in 50 minutes. The cobalt ferrite-based nanocomposite for such a degradation strategy is not endorsed by any such literature. In conclusion, the current finding can be said to be novel and widely recognized at the industrial scale to mitigate aquatic contamination from a hazardous dye such as aniline blue. This finding expands further scope to extrapolate the current work on environmental contamination mitigation in the future.

\section{Declarations}

\section{Acknowledgements:}

The authors are appreciative to the Department of Chemistry, NIT Silchar, the Department of Chemistry, S. S. College, Hailakandi, and G. C. College, Silchar, Assam, India, for providing the research infrastructure. The authors would also like to appreciate STIC, Cochin, Kerala; and SAIC, Tezpur University, Assam for providing analytical amenities.

Ethical Approval: Not applicable

Consent to Participate: The authors have given their full consent to participate in the publishing process.

Consent to Publish: The authors have given their full consent to publish the paper if accepted by the journal.

Authors Contribution: D.G.T. (Ph.D. Student) has conducted all experiments and prepares the manuscript, K.C.D. (Associate professor) helps in characterization process and revised the manuscript and S.S.D. (Associate Professor) helps in entire supervision. Every one of the authors offered constructive feedback and supported in the development of the research, analysis, and manuscript. 
Funding: As this is a self-funded Ph. D initiative, no funds have been allocated for this current research.

Competing interests: There have been no competing interests declared by the authors.

Data Availability: On reasonable request, the corresponding author can provide the datasets used and/or analyzed during the present study.

\section{References}

Alnuaimi, M. M., Rauf, M. A., \& Ashraf, S. S. (2007). Comparative decoloration study of Neutral Red by different oxidative processes. Dyes and Pigments, 72(3), 367-371.

Ao, Y., Xu, J., Fu, D., Shen, X., \& Yuan, C. (2008). A novel magnetically separable composite photocatalyst: titania-coated magnetic activated carbon. Separation and Purification Technology, 61(3), 436-441.

Azmi, W., Sani, R. K., \& Banerjee, U. C. (1998). Biodegradation of triphenylmethane dyes. Enzyme and microbial technology, 22(3), 185-191.

Bouasla, C., Samar, M. E. H., \& Ismail, F. (2010). Degradation of methyl violet 6 B dye by the Fenton process. Desalination, 254(1-3), 35-41.

Bunaciu, A. A., UdrişTioiu, E. G., \&Aboul-Enein, H. Y. (2015). X-ray diffraction: instrumentation and applications. Critical reviews in analytical chemistry, 45(4), 289-299.

Culp, S. J., \& Beland, F. A. (1996). Malachite green: a toxicological review. Journal of the American College of Toxicology, 15(3), 219-238.

Daneshvar, N., Salari, D., \&Khataee, A. R. (2003). Photocatalytic degradation of azo dye acid red 14 in water: investigation of the effect of operational parameters. Journal of Photochemistry and Photobiology A: Chemistry, 157(1), 111-116.

Das, K. C., \& Dhar, S. S. (2020). Remarkable catalytic degradation of malachite green by zinc supported on hydroxyapatite encapsulated magnesium ferrite $\left(\mathrm{Zn} / \mathrm{HAP} / \mathrm{MgFe}_{2} \mathrm{O}_{4}\right)$ magnetic novel nanocomposite. Journal of Materials Science, 55(11), 4592-4606.

De Souza, V. B., Thomazini, M., Barrientos, M. A. E., Nalin, C. M., Ferro-Furtado, R., Genovese, M. I., \&Favaro-Trindade, C. S. (2018). Functional properties and encapsulation of a proanthocyanidin-rich cinnamon extract (Cinnamomum zeylanicum) by complex coacervation using gelatin and different polysaccharides. Food Hydrocolloids, 77, 297-306.

Deraz, N. M. (2010). Glycine-assisted fabrication of nanocrystalline cobalt ferrite system. Journal of Analytical and Applied Pyrolysis, 88(2), 103-109. 
Devi, L. G., Kottam, N., Murthy, B. N., \& Kumar, S. G. (2010). Enhanced photocatalytic activity of transition metal ions $\mathrm{Mn}^{2+}, \mathrm{Ni}^{2+}$ and $\mathrm{Zn}^{2+}$ doped polycrystalline titania for the degradation of Aniline Blue under UV/solar light. Journal of Molecular Catalysis A: Chemical, 328(1-2), 44-52.

Devi, L. G., Kottam, N., Murthy, B. N., \& Kumar, S. G. (2010). Enhanced photocatalytic activity of transition metal ions $\mathrm{Mn}^{2+}, \mathrm{Ni}^{2+}$ and $\mathrm{Zn}^{2+}$ doped polycrystalline titania for the degradation of Aniline Blue under UV/solar light. Journal of Molecular Catalysis A: Chemical, 328(1-2), 44-52.

Dom, R., Subasri, R., Radha, K., \&Borse, P. H. (2011). Synthesis of solar active nanocrystalline ferrite, $\mathrm{MFe}_{2} \mathrm{O}_{4}$ (M: Ca, Zn, Mg) photocatalyst by microwave irradiation. Solid State Communications, 151(6), 470-473.

Egzar, H. K., Mashkour, M. S., \& Juda, A. M. (2013). Study the Photo degradation of Aniline Blue dye in aqueous Phase by using Different Photo catalysts. Asian Transactions on Basic and Applied Sciences, 3(2), 23-28.

Egzar, H. K., Mashkour, M. S., \& Juda, A. M. (2013). Study the Photodegradation of Aniline Blue dye in aqueous Phase by using Different Photocatalysts. Asian Transactions on Basic and Applied Sciences, 3(2), 23-28.

Egzar, H. K., Mashkour, M. S., \& Juda, A. M. (2013). Study the Photodegradation of Aniline Blue dye in aqueous Phase by using Different Photocatalysts. Asian Transactions on Basic and Applied Sciences, 3(2), 23-28.

Eykholt, G. R., \& Davenport, D. T. (1998). Dechlorination of the chloroacetanilide herbicides alachlor and metolachlor by iron metal. Environmental science \& technology, 32(10), 1482-1487.

Hayati, B., \& Mahmoodi, N. M. (2012). Modification of activated carbon by the alkaline treatment to remove the dyes from wastewater: mechanism, isotherm and kinetic. Desalination and Water Treatment, 47(1-3), 322-333.

Hebbar, R. S., Isloor, A. M., Prabhu, B., Asiri, A. M., \& Ismail, A. F. (2018). Removal of metal ions and humic acids through polyetherimide membrane with grafted bentonite clay. Scientific reports, 8(1), 1-16.

Kooti, M., Saiahi, S., \&Motamedi, H. (2013). Fabrication of silver-coated cobalt ferrite nanocomposite and the study of its antibacterial activity. Journal of magnetism and magnetic materials, 333, 138-143.

Ledakowicz, S., \&Gonera, M. (1999). Optimisation of oxidants dose for combined chemical and biological treatment of textile wastewater. Water research, 33(11), 2511-2516.

Lee, J. H., Ahn, H. J., Youn, J. I., Kim, Y. J., Suh, S. J., \& Oh, H. J. (2018). Synthesis and Characterization of $\mathrm{ZnO} / \mathrm{TiO} 2$ Photocatalyst Decorated with PbS QDs for the Degradation of Aniline Blue Solution. Korean Journal of Metals and Materials, 56(12), 900-909. 
Lee, J. H., Ahn, H. J., Youn, J. I., Kim, Y. J., Suh, S. J., \& Oh, H. J. (2018). Synthesis and characterization of $\mathrm{ZnO} / \mathrm{TiO} 2$ photocatalyst decorated with PbS QDs for the degradation of aniline blue solution. Korean Journal of Metals and Materials, 56(12), 900-909.

Liu, D. R., Jiang, Y. S., \& Gao, G. M. (2011). Photocatalytic degradation of an azo dye using N-doped $\mathrm{NaTaO}_{3}$ synthesized by one-step hydrothermal process. Chemosphere, 83(11), 1546-1552.

Lorenc-Grabowska, E., \&Gryglewicz, G. (2007). Adsorption characteristics of Congo Red on coal-based mesoporous activated carbon. Dyes and pigments, 74(1), 34-40.

Machala, L., Tucek, J., \&Zboril, R. (2011). Polymorphous transformations of nanometric iron (III) oxide: a review. Chemistry of Materials, 23(14), 3255-3272.

Man, L. W., Kumar, P., Teng, T. T., \&Wasewar, K. L. (2012). Design of experiments for Malachite Green dye removal from wastewater using thermolysis-coagulation-flocculation. Desalination and Water Treatment, 4O(1-3), 260-271.

Mushtaq, F., Zahid, M., Mansha, A., Bhatti, I. A., Mustafa, G., Nasir, S., \& Yaseen, M. (2020). $\mathrm{MnFe}_{2} \mathrm{O}_{4} / \mathrm{coal}$ fly ash nanocomposite: a novel sunlight-active magnetic photocatalyst for dye degradation. International Journal of Environmental Science and Technology, 17, 4233-4248.

Ooi, B. S., Sum, J. Y., \& Lai, S. O. (2012). Investigation on membrane morphological and chemical properties changes at different reaction times and its effect on dye removal. Desalination and Water Treatment, 45(1-3), 250-255.

Pare, B., Soni, A., \& Bhagwat, V. W. (2008). Kinetics of reduction of aniline blue dye using zero valent ironj $\left(\mathrm{Fe}^{0}\right)$ Rasayan Journal of Chemistry, 1, 413-420.

Rauf, M. A., \& Ashraf, S. S. (2009). Fundamental principles and application of heterogeneous photocatalytic degradation of dyes in solution. Chemical engineering journal, 151(1-3), 10-18.

Rauf, M. A., \& Ashraf, S. S. (2012). Survey of recent trends in biochemically assisted degradation of dyes. Chemical engineering journal, 209, 520-530.

Rubio, D., Nebot, E., Casanueva, J. F., \&Pulgarin, C. (2013). Comparative effect of simulated solar light, UV, $\mathrm{UV} / \mathrm{H} \otimes \mathrm{O} \otimes$ and photo-Fenton treatment (UV-Vis/ $\left.\mathrm{H} \otimes \mathrm{O} \otimes / \mathrm{Fe}^{2} \rrbracket,{ }^{3} \rrbracket\right)$ in the Escherichia coli inactivation in artificial seawater. Water research.

Shi, L., Liang, L., Wang, F., Liu, M., Chen, K., Sun, K. \& Sun, J. (2015). Higher yield urea-derived polymeric graphitic carbon nitride with mesoporous structure and superior visible-light-responsive activity. ACS Sustainable Chemistry \& Engineering, 3(12), 3412-3419.

Sirés, I., Guivarch, E., Oturan, N., \&Oturan, M. A. (2008). Efficient removal of triphenylmethane dyes from aqueous medium by in situ electrogenerated Fenton's reagent at carbon-felt 
cathode. Chemosphere, 72(4), 592-600.

Sun, J. H., Sun, S. P., Fan, M. H., Guo, H. Q., Qiao, L. P., \& Sun, R. X. (2007). A kinetic study on the degradation of p-nitroaniline by Fenton oxidation process. Journal of hazardous materials, 148(1-2), 172177.

Vijayaraghavan, T., Suriyaraj, S. P., Selvakumar, R., Venkateswaran, R., \& Ashok, A. (2016). Rapid and efficient visible light photocatalytic dye degradation using $\mathrm{AFe}_{2} \mathrm{O}_{4}(\mathrm{~A}=\mathrm{Ba}, \mathrm{Ca}$ and $\mathrm{Sr})$ complex oxides. Materials Science and Engineering: B, 210, 43-50.

Zhang, H., Fei, C., Zhang, D., \& Tang, F. (2007). Degradation of 4-nitrophenol in aqueous medium by electro-Fenton method. Journal of hazardous materials, 145(1-2), 227-232.

\section{Figures}

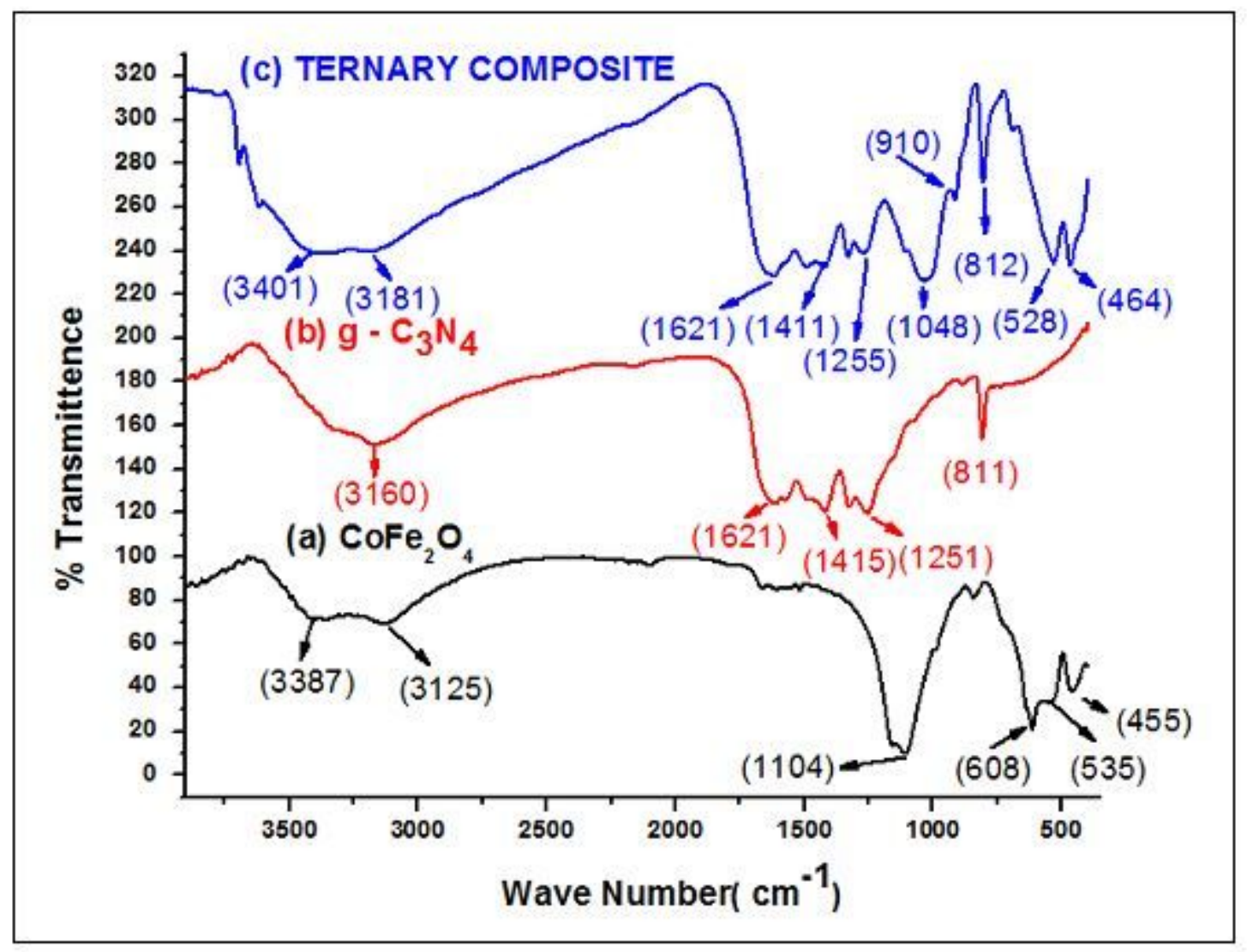

Figure 1

FTIR of Cobalt ferrite (a), Graphitic Carbon Nitride (b), and Ternary Composite (c). 


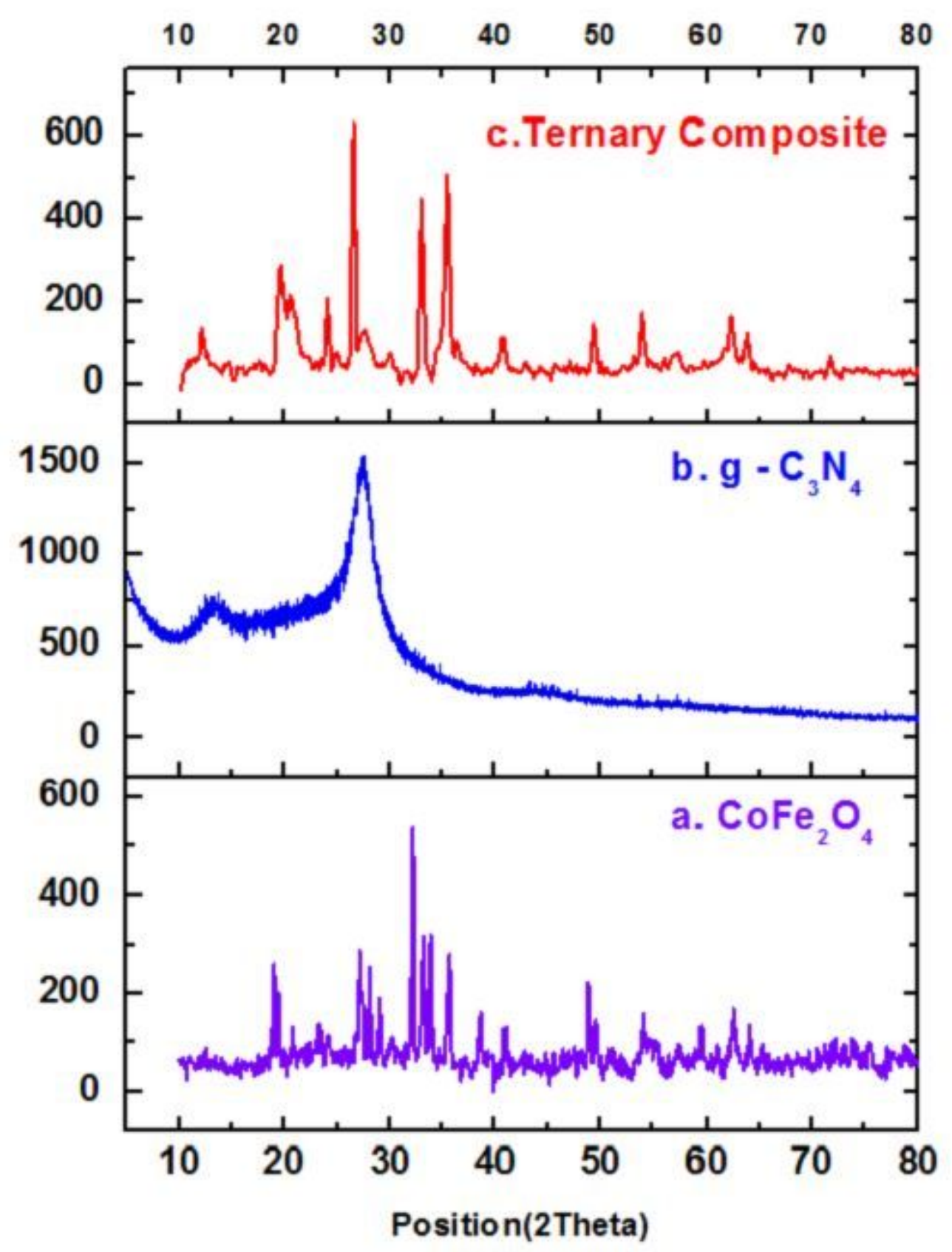

Figure 2

XRD pattern of Cobalt ferrite (a), g-C3N4 (b) and Ternary Composite (b). 




Figure 3

Hysteresis curves obtained from VSM analysis Cobalt ferrite (a) and Ternary Composite (b).

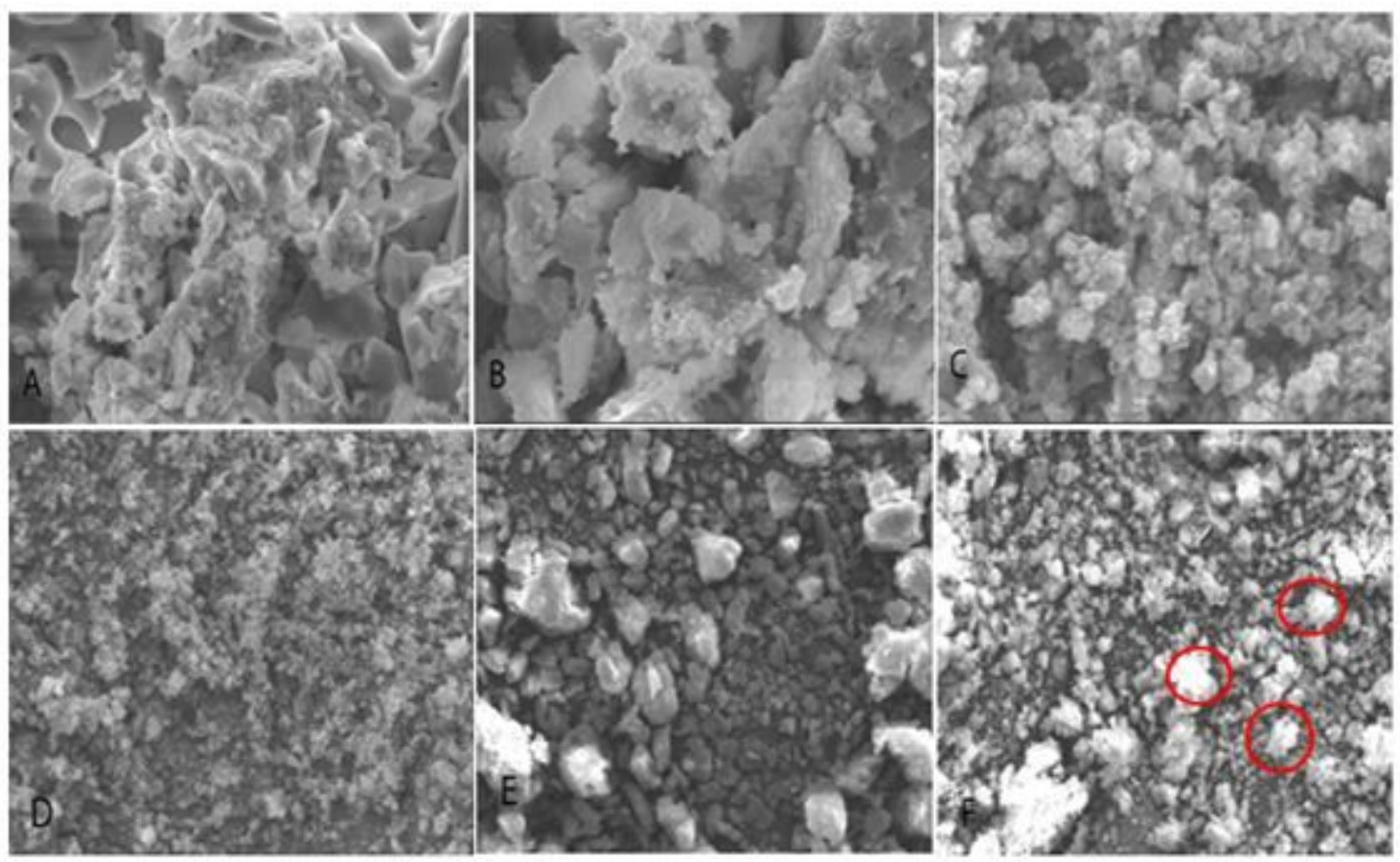

Figure 4

SEM image of Cobalt ferrite $(A, B)$, graphitic carbon nitride $(C, D)$, bentonite $(E)$ and ternary nanocomposite $(F)$. 

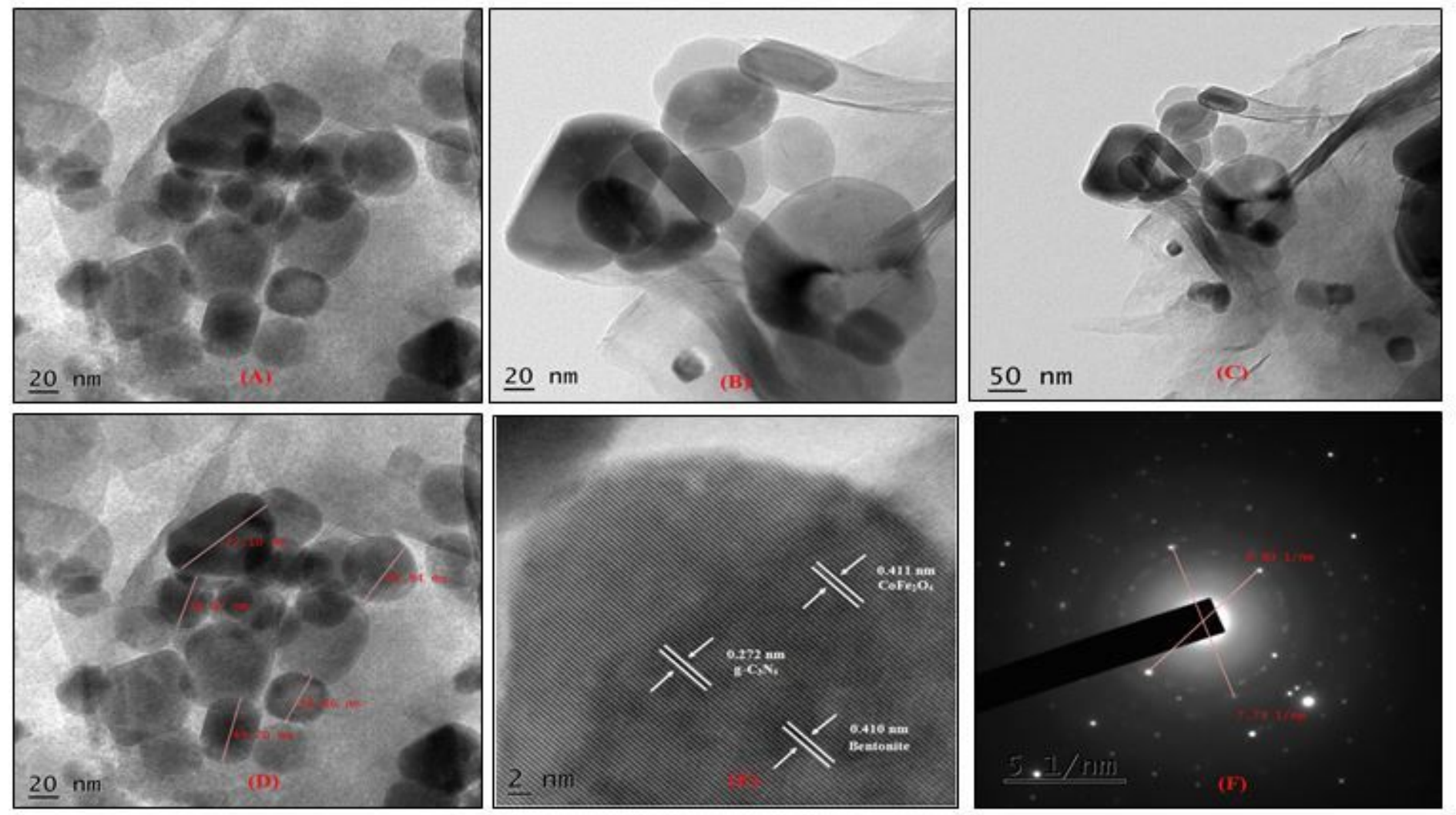

\section{Figure 5}

TEM image (A, B, C, D), HR-TEM (E) and SAED pattern (F) of the ternary nanocomposite.

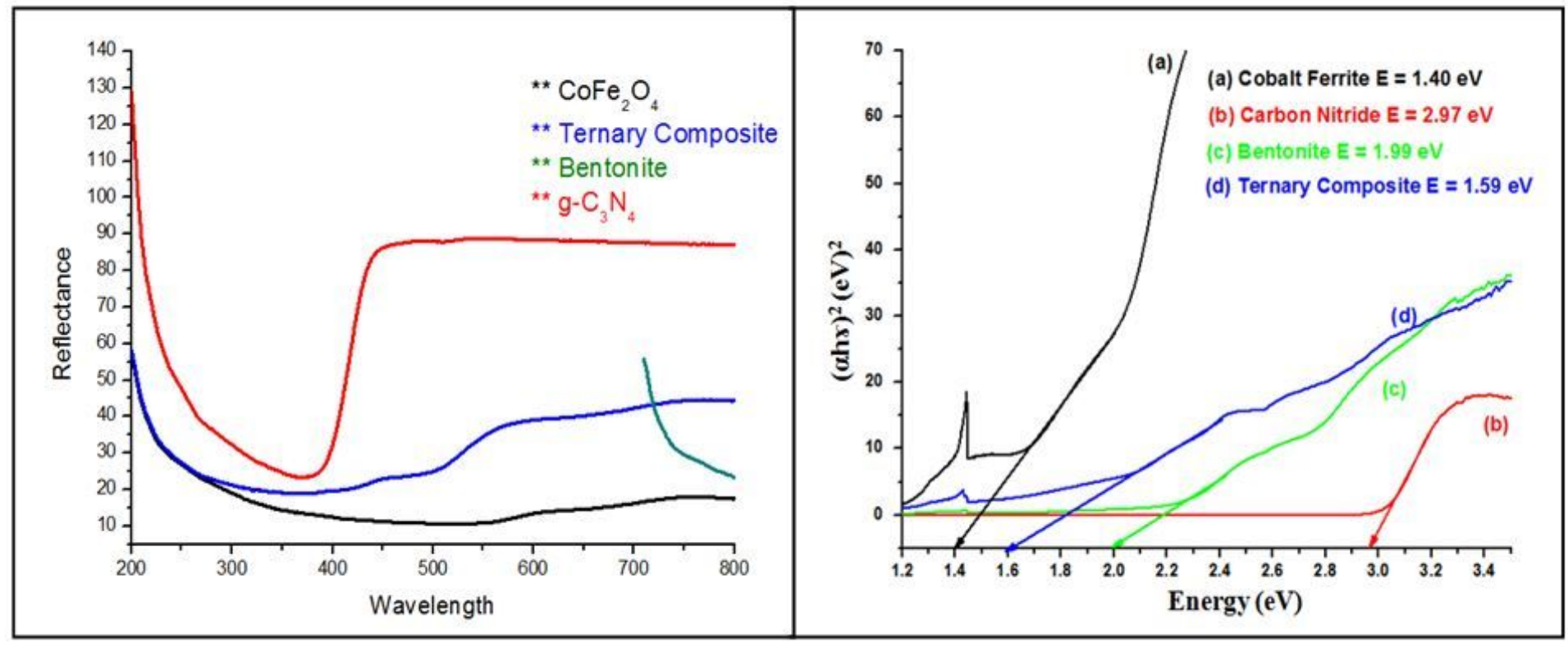

\section{Figure 6}

UV-DRS absorbance spectrum of CoFe204, graphitic nitride, bentonite and the ternary composite (wavelength reflectance and Tauc's plot) 

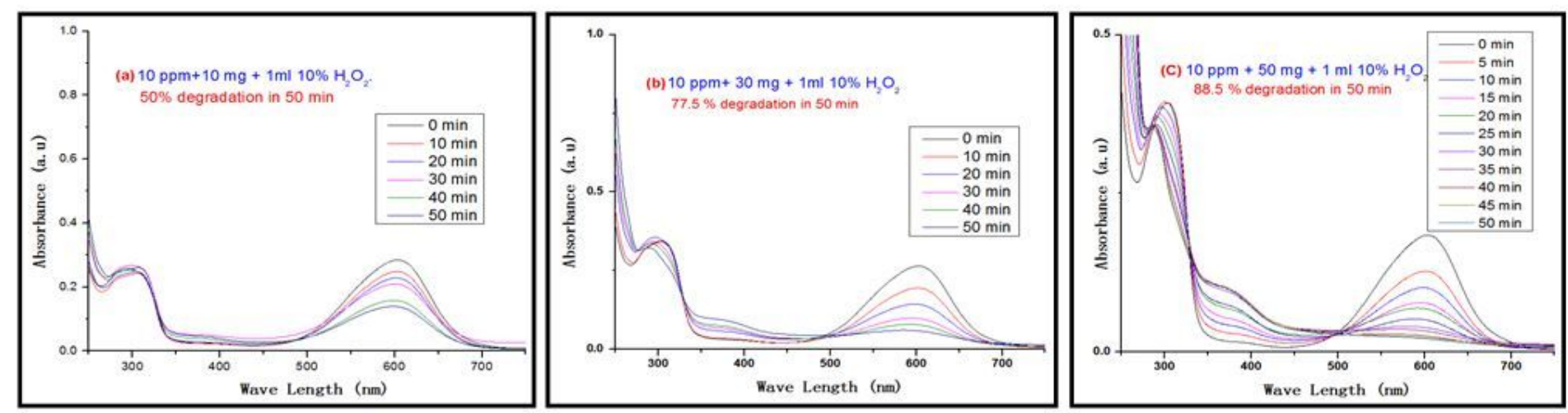

Figure 7

Absorbance alteration of the degradation of aniline blue (10 ppm) for (a) $10 \mathrm{mg}$, (b) $30 \mathrm{mg}$ and (c) $50 \mathrm{mg}$ composite respectively in presence of $1 \mathrm{ml}$ of $10 \% \mathrm{H} 2 \mathrm{O} 2$
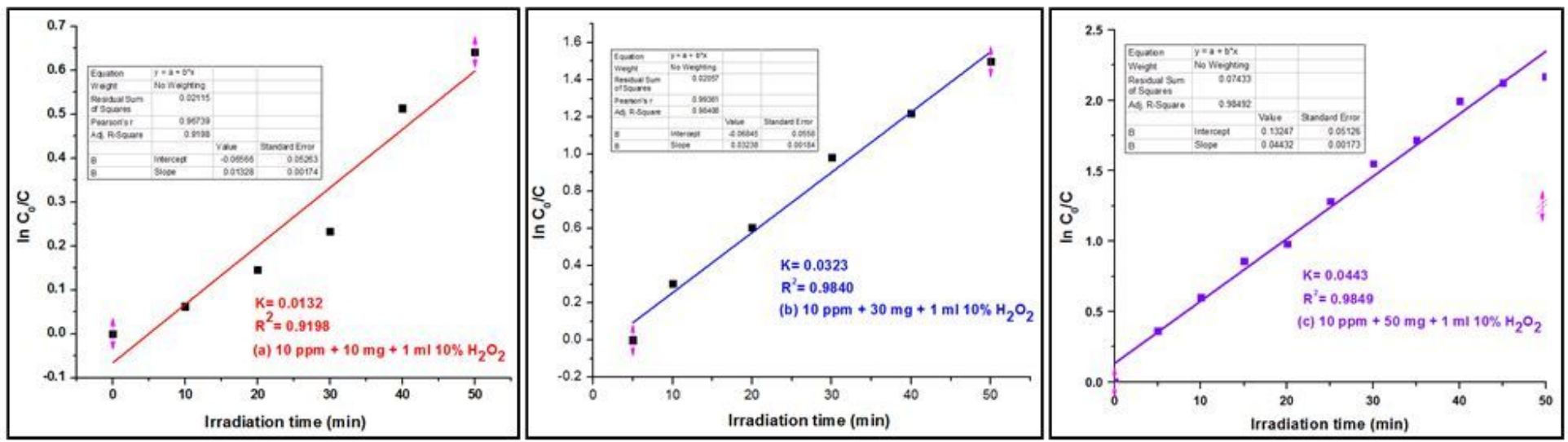

Figure 8

Plots of InC0 /C against irradiation time for (a) $10 \mathrm{mg}$ (b) $30 \mathrm{mg}$ (c) $50 \mathrm{mg}$ composite
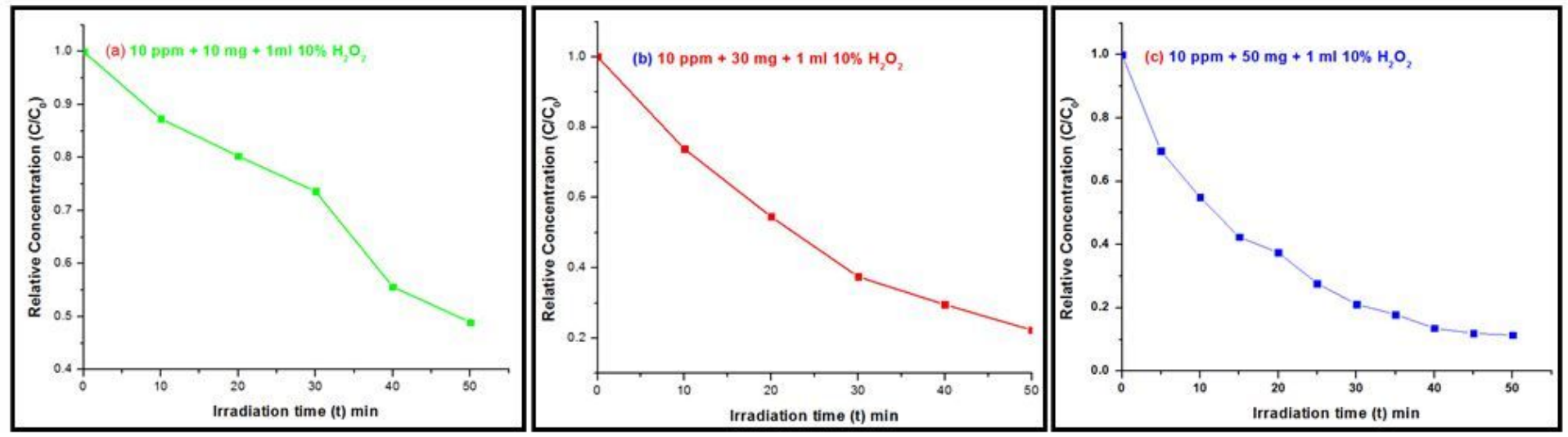

Figure 9

Plots of $\mathrm{C} / \mathrm{CO}$ against irradiation time for (a) $10 \mathrm{mg}$ (b) $30 \mathrm{mg}$ (c) $50 \mathrm{mg}$ composite. 


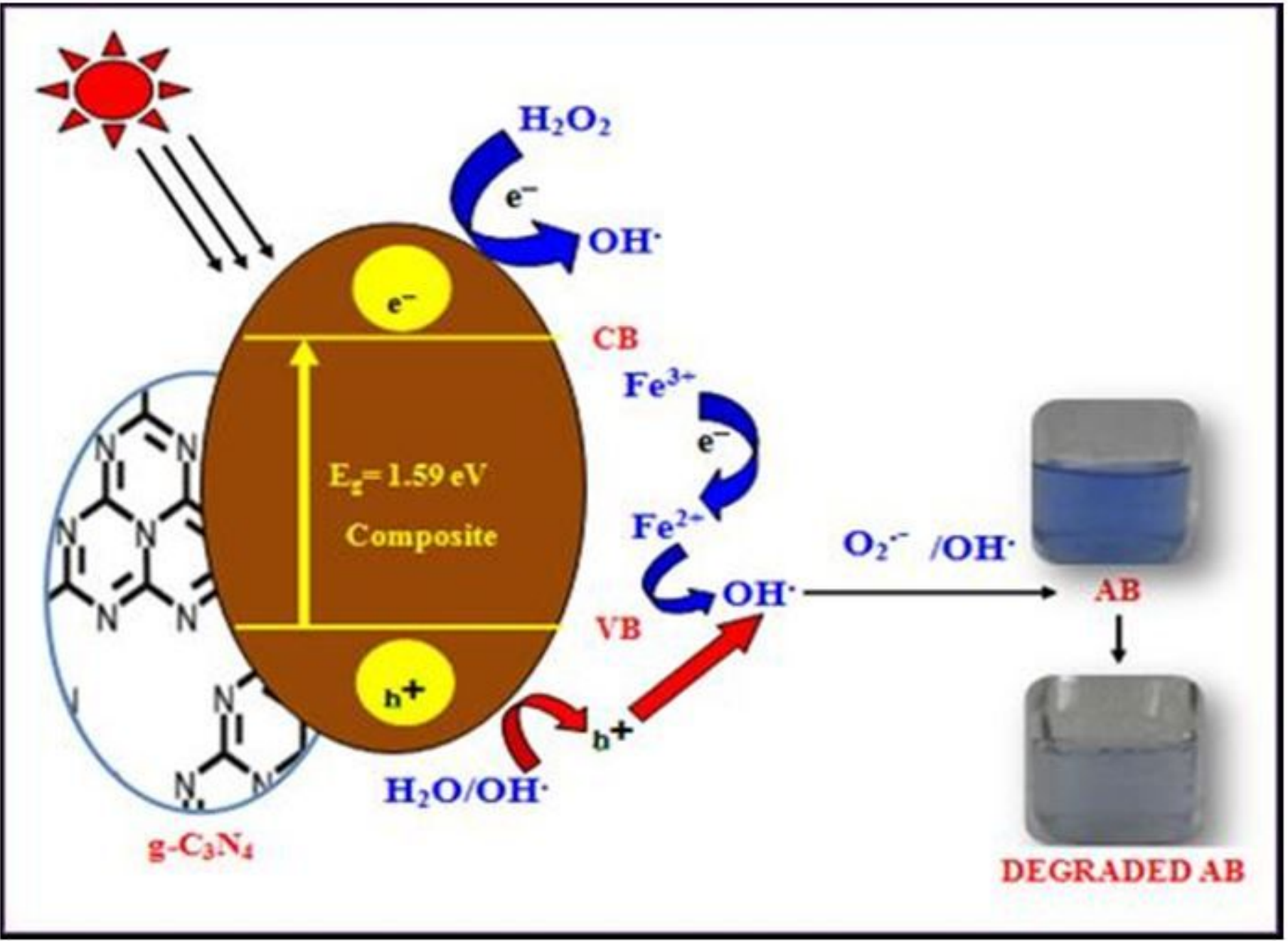

Figure 10

Plausible mechanism of degradation of $A B$

\section{Supplementary Files}

This is a list of supplementary files associated with this preprint. Click to download.

- formulaandreactions.docx 